This item was submitted to Loughborough's Research Repository by the author.

Items in Figshare are protected by copyright, with all rights reserved, unless otherwise indicated.

\title{
Vehicle crashworthiness and the older motorist
}

PLEASE CITE THE PUBLISHED VERSION

PUBLISHER

(c) Cambridge University Press

LICENCE

CC BY-NC-ND 4.0

\section{REPOSITORY RECORD}

Morris, Andrew, Ruth Welsh, Richard Frampton, Jude Charlton, and Brian Fildes. 2019. "Vehicle Crashworthiness and the Older Motorist”. figshare. https://hdl.handle.net/2134/1123. 


\title{
Vehicle crashworthiness and the older motorist
}

\author{
ANDREW MORRIS*, RUTH WELSH*, RICHARD FRAMPTON*, \\ JUDE CHARLTON $\dagger$ and BRIAN FILDES $\dagger$
}

\begin{abstract}
This study examines the relationship between age and the injury outcomes for belted drivers in road vehicle crashes in the United Kingdom. The sample of I,54I drivers was divided into three age groups: 889 drivers were aged I7-39 years (young drivers); 515 were 40-64 years (middle-aged), and I37 aged 65-84 years (older drivers). Both frontal and side impact crashes in which the vehicles sustained sufficient damage to be towed away from the scene are considered. Indepth information obtained from examinations of the crashed vehicles was combined with clinical data obtained from hospitals to throw light on the mechanisms that led to the injuries. Results show that in crashes of approximately equal severity, older drivers were significantly more likely than middle-aged and young drivers to be fatally injured in both frontal $(p<$ o.ooI $)$ and side $(p<0.05)$ impact crashes. The results also show that older drivers sustained more injuries to the chest $(p<$ o.ooor $)$ and that this body region is particularly problematic. The main sources of the chest injuries were found to be the seat belt in frontal crashes and the door in side impact crashes. As the number of older car users will increase rapidly in most OECD countries in the coming decades, the results suggest that vehicle re-designs are required, including in-vehicle crashworthiness systems, to take into account older people's relatively low tolerance of crash impacts.
\end{abstract}

$\boldsymbol{K E Y} \boldsymbol{W} \boldsymbol{O R D S}$ - vehicle accidents, accidental injuries, accident analysis, chest injuries, head injuries.

\section{Introduction}

It is generally acknowledged that the energy required to cause an injury reduces as a person ages (Augenstein 200I). It therefore follows that older drivers are more vulnerable to injury in a crash. Their skeletal structures

* Vehicle Safety Research Centre, Loughborough University, UK.

$\dagger$ Monash University Accident Research Centre, Clayton, Victoria, Australia. 
are more easily damaged and the consequences of any assault are likely to be more serious as compared with younger drivers (Dejammes and Ramet I996; Evans I99I; Mackay I989; Viano et al. I989). As the population ages, there is a growing awareness of the need for vehicles that are safe for older occupants. In short, to provide better protection for older drivers in the event of a crash, there is a need to improve the crashworthiness of vehicles.

The level of personal mobility and independence afforded by the motor car is valued highly by older people, and an increasing number in western countries own their own car and make an overwhelming proportion of their trips in private vehicles (Organisation for Economic Co-operation and Development (OECD) 200I). Over the next three decades, this pattern is likely to intensify at a rate at least consistent with the growth in the number of older people. In many OECD countries, by the year 2030 one in every four persons will be aged 65 or more years. The next generations of older drivers will bring a new set of challenges for road safety. The baby-boom generation will have grown up with the car, have higher car driving licence rates, and will travel longer distances by car than their parents' generation. As a consequence of the increased number of older drivers and their greater reliance on cars for mobility, older driver safety is likely to become an ever more important issue.

Some research suggests that older drivers do not represent a large road safety problem, as indicated by the number of their crashes. Older adults generally travel less, however, so when crash statistics are adjusted for distance travelled, their relative vulnerability becomes clear. Recent findings show that older drivers, particularly those aged over 75 years, are more likely to be involved in a serious injury crash per kilometre driven than other age groups (Diamantopoulou et al. 1996). In addition, as Australian fatality data for 1998 demonstrate, drivers aged 75 or more years have a much higher risk than other adult age groups of being killed per kilometre travelled (Fildes et al. 200I). Indeed, in all OECD member countries, older drivers have higher fatality rates than other age groups. Figure I shows the fatality rate per journey by age group in Great Britain in 1998 (Mitchell 2000, cited in OECD 200I). The fatality rate for car drivers rises gradually from around 45 to 65 years of age, and a steep increase is observed for drivers aged more than 70 years. A similar pattern is observed for car passengers up until the age of 75 years, with a plateau beyond this age group. It is their vulnerability that is partially responsible for the over-representation of older occupants in fatal and serious injury crashes (Cunningham et al. 200I).

While the current crash figures for older drivers pose a major concern for road safety, expected changes in the population are likely to magnify 


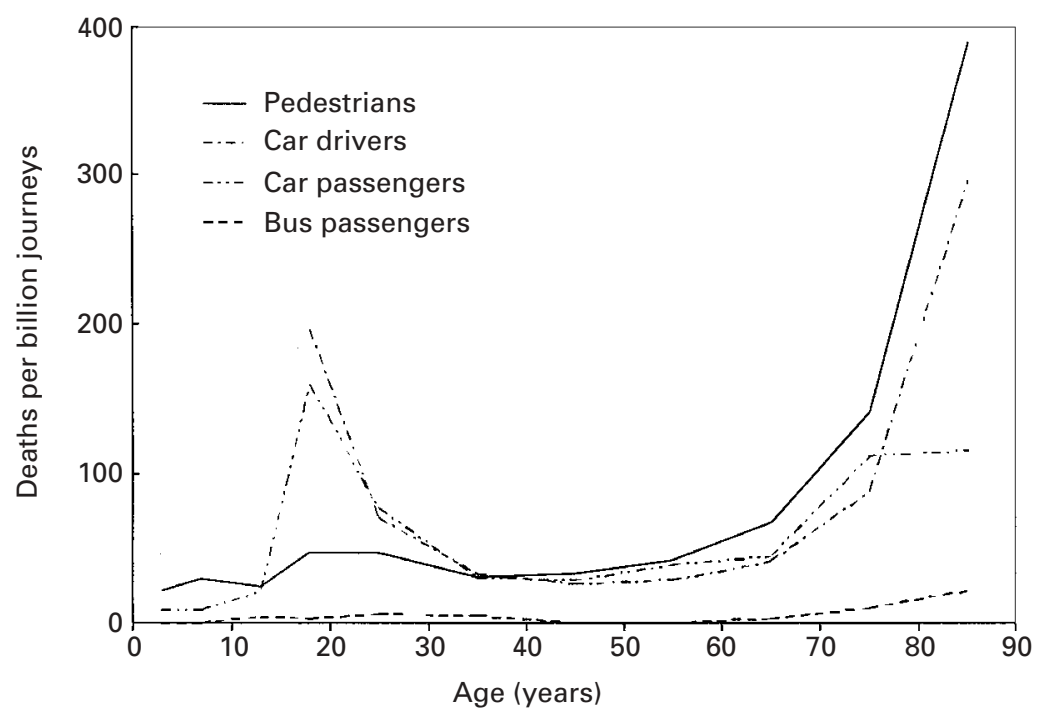

Figure I. Fatality rate per journey by mode of transport and age, Great Britain I998.

the problem. United States research suggests that without active intervention, over the next three decades fatal crashes could increase three times $(\mathrm{Hu}$ et al. 2000). The model employed predicts a 286 per cent increase in older driver fatalities. It is predicated on four key factors: an increase in the proportion of older people in the population; an increase in the distance travelled by this group; an increase in the number of licensed older drivers; and an increase in their crash risk. The last is attributed to declining visual, physical and cognitive skills as a function of the increasing average age of the older population. Using Hu's model, Fildes et al. (200I) showed that similar patterns of increase in fatality rates were likely in Australia.

Although there are a lot of data concerning the declining driving competence associated with personal ageing, and there has been considerable research into in-vehicle counter-measures, the relationships between age and the injury outcomes of vehicle crashes are largely unknown. The ageing process is thought to reduce tolerance to crash forces, through reduced bone strength and fracture tolerance (Mackay I989; Viano et al. I989). The high prevalence of osteoporosis, particularly among women, is well established (Berthel et al. 1980). Nevertheless, although manufacturers have an increasing awareness of the physiological changes that take place in later life, the evidence upon which effective crash protection design is based is sparse, particularly regarding the needs of older drivers (Mackay 
I989). In one study, Foret-Bruno (1978, I989; cited in Dejammes and Ramet 1996) concluded that older people could withstand a chest load of 5 ,ooo Newtons, ${ }^{1}$ whilst young people could withstand 8,00o Newtons. The implication is that an older car occupant is several times more likely to sustain a life-threatening chest injury as occur in relatively moderate crashes (Augenstein 200I; Padmanaban 200I). The chest is clearly vulnerable both as a principal point of contact with the vehicle in a crash and as the major load-bearing area of the body for restraint systems. The paper reports findings from the first detailed study of the older vehicle occupant in vehicle crashes. As noted by Mackay and Hassan (2000), a great deal more data are needed if manufacturers are to improve vehicle performance (or response) in crashes.

\section{Data, indicators and methods}

In-depth crash injury data for the United Kingdom that cover currentmodel cars are analysed in this study. They were collected between I998 and 200I as part of the 'Co-operative Crash Injury Study' (CCIS). The CGIS data are a stratified sample of UK crashes from which the vehicle was towed away. According to the UK government's classification, some 80 per cent of 'serious' and 'fatal' (and Io-I5 per cent of 'slight') injury crashes are investigated in defined sample regions. Consequently, the resulting sample is biased towards the more serious crashes, and there is a possibility of a regional bias reflecting the selected study regions.

In total, some I,54I single impact vehicle crashes were studied. The unweighted sample includes only belted drivers, including 889 drivers aged between ${ }^{1} 7-39$ years (young drivers), $5^{\mathrm{I}} 5$ aged $4 \mathrm{O}-64$ years (middleaged), and 137 aged $65^{-84}$ years (older). Medical data were obtained from the hospitals to which the drivers were admitted. The sampling criteria determined that all vehicles in the study were less than six years old at the time of the crash, and that an in-depth examination of each vehicle was made within a few days of the accident in the recovery-yards and garages to which they were towed. The government classification of injuries was used to assess and compare the severity of the drivers' injuries:

Fatal Death within 30 days of the crash.

Serious Injuries serious enough to warrant hospitalisation, or serious injuries such as fractures and severe lacerations.

Slight Injury requiring minor treatment at an outpatient ward or at the roadside.

No injury No reported or observed injury. 


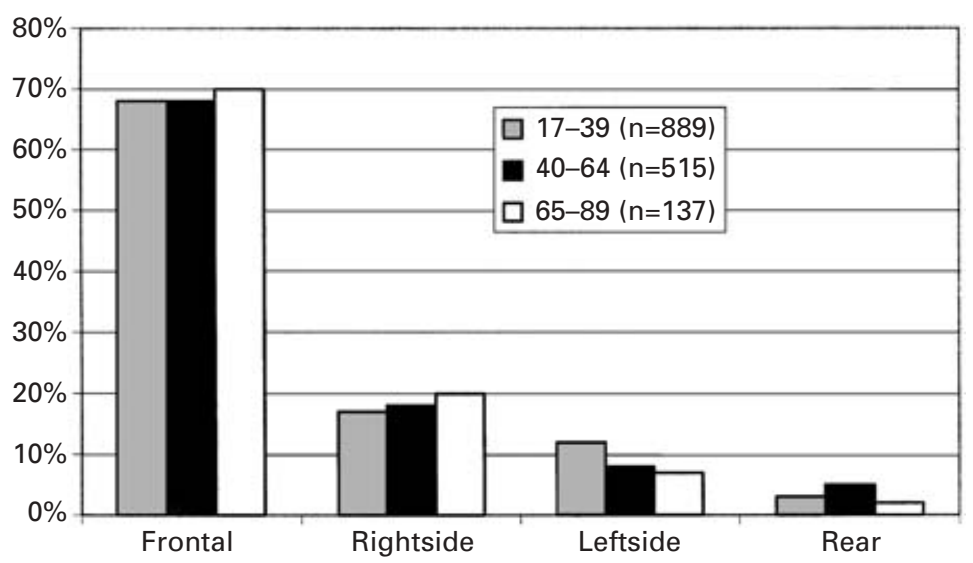

Figure 2. Crash type by age group of driver, UK I998-200I.

Individual injuries were coded and described according to the 'Abbreviated Injury Scale' (AIS) I990 revision. This ordinal scale classifies injuries on a 'threat-to-life' scale from I (minor) to 6 (maximum severity) where:

$\mathrm{I}=$ minor, e.g. bruise, abrasion

$2=$ moderate, e.g. simple limb fracture

$3=$ serious, e.g. base of skull fracture

$4=$ severe, e.g. major liver laceration

$5=$ critical, e.g. major aortic tear

$6=$ maximum, e.g. decapitation

The 'Maximum Abbreviated Injury Score' (MAIS) was also used where possible. This is the highest AIS injury sustained by the driver in the crash, and it is scored from ' 0 ' (no injury) to ' 6 ' (maximum injury). Passengers were not considered in this study. The chi-squared test was used to examine the relationship between the three age groups and several independent variables of interest. In addition, one-way analyses of variance (ANOVA) were used to investigate differences in crash severity across the three age groups for each crash classification of interest. ${ }^{2}$

\section{Results}

Characteristics of older drivers' crashes

The first set of results examines some characteristics of older driver crashes when compared to those of younger drivers. Figure 2 shows crash types by the drivers' age groups. A chi-square test supports the hypothesis of no relationship between crash type and age group, although older drivers 


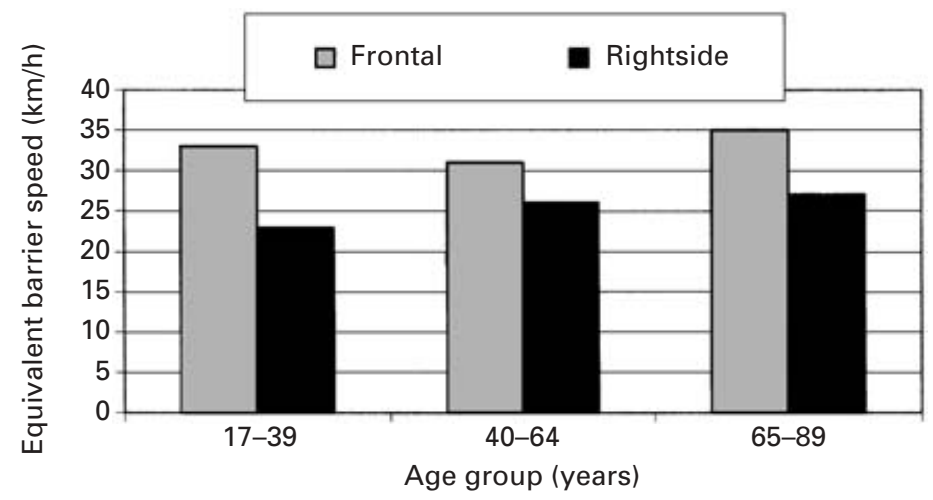

Figure 3. Crash severity by driver age (belted drivers).

were involved in slightly more frontal and struck-side (i.e. driver or rightside) crashes, and slightly fewer non-struck side (left-side) and rear impacts compared to young and middle-aged drivers. The number of steering wheel mounted airbag deployments in frontal crashes was also examined: they occurred in 46 per cent of the crashes involving i7-39 year old drivers, 47 per cent of $40^{-}-64$ year old drivers, and 48 per cent of 65 or more years old drivers.

Figure 3 shows the crash severity for the three age groups according to crash type. Only frontal and right-side crashes have been studied in this analysis. There appears to be little difference in the mean severity of frontal impacts among the three age groups, as measured by the 'Equivalent Barrier Speed' (EBS). ${ }^{3}$ In support, an ANOVA for each impact type produced non-significant results. The collision severity by airbag deployment and age group was also examined for frontal impacts and showed little variation (Table I). As there were no cases of side impact airbag deployments in the sample, this analysis was not repeated for rightside crashes. It should also be noted that collision severity could not be obtained for all crashes.

\section{Injury severity and the age of drivers}

Table 2 shows the injury outcomes by crash type for the three age groups of drivers. Older drivers appear to be over-represented in 'fatal' injuries from frontal impact crashes. A chi-squared test supports $(p \leqslant 0.05)$ rejection of the null hypothesis of equal distributions, even though, as shown above, the nature and severity of crashes in which they were involved were not statistically different from those experienced by the other age groups. When side impacts are considered, the chi-square statistic supports the 
T A B L E I. Frontal impact crash severity by airbag deployment and driver age group, United Kingdom, 1998-200I

\begin{tabular}{lcccccc}
\hline & \multicolumn{6}{c}{ Age group (years) } \\
\cline { 2 - 7 } & \multicolumn{2}{c}{ I7-39 } & \multicolumn{2}{c}{$40-64$} & \multicolumn{2}{c}{65 or more } \\
\hline Airbag* & No & Yes & No & Yes & No & Yes \\
Mean EBS & 32.0 & $33 \cdot$ I & 32.0 & 30.3 & 36.1 & $33 \cdot 5$ \\
N & 242 & 219 & I34 & I22 & 40 & 39 \\
\hline
\end{tabular}

Notes: EBS = equivalent barrier speed in kilometres per hour. $*$ No airbag $=$ no steering-wheel airbag fitted or no deployment. Airbag= steering wheel airbag fitted and deployed.

$\mathrm{T}$ A B L E 2. Injury severity in frontal and side impacts by driver age group

\begin{tabular}{lccc}
\hline & \multicolumn{3}{c}{ Age group (years) } \\
\cline { 2 - 4 } Injury classification & ${ }^{17-39(\%)}$ & $40-64(\%)$ & $65+(\%)$ \\
\hline Frontal crashes & 3 & 3 & I5 \\
Fatal & 28 & 34 & 35 \\
Serious & 60 & 54 & 43 \\
Slight & 9 & 9 & 7 \\
Uninjured & & & 2 I \\
Side crashes & 7 & II & 36 \\
Fatal & 33 & 62 & 39 \\
Serious & 55 & 9 & 4 \\
Slight & 5 & & \\
Uninjured & & & \\
& & & \\
\end{tabular}

Notes: The four severity labels are as defined in the United Kingdom government classification. Test statistics for (a) frontal impacts: $\chi^{2}=34.8$, d.f. $=6, p<0.00$; and (b) side impacts: $\chi^{2}=$ I 4.05 , d.f. $=6$, $p<0.05$.

hypothesis that driver injury severity varied by driver age, and older drivers were again over-represented in the 'fatal' category. It can also be seen from Table 2 that a higher proportion of the younger than the middle-aged drivers sustained serious injuries. The reason for this is not immediately clear: possible explanations include differences in the objects that were struck, in the type and size of vehicles, and unmeasured factors.

The influence of the driver airbag on injury outcomes in frontal impacts was also examined. Table 3 shows crash severity by airbag deployment for each of the age groups. It should be noted that older drivers were most likely to be involved in crashes of high severity, and that when airbags were not deployed, nearly one-fifth (18\%) of them sustained fatal injuries. Airbag effectiveness in frontal crashes was not studied in its entirety, partly because of the absence of side impact deployments, but also because numerous factors influence crash outcomes in these cases. Table 4 show actual injury outcomes (according to the MAIS scores) by crash type and 
T A в L E 3. Injury outcome by airbag deployment and age group

\begin{tabular}{|c|c|c|c|c|c|c|}
\hline \multirow[b]{3}{*}{ Airbag } & \multicolumn{6}{|c|}{ Age group (years) } \\
\hline & \multicolumn{2}{|c|}{$17-39(\%)$} & \multicolumn{2}{|c|}{$40-64(\%)$} & \multicolumn{2}{|c|}{$65+(\%)$} \\
\hline & No & Yes & No & Yes & No & Yes \\
\hline Fatal & 2.5 & 4.0 & 3.2 & 3.0 & I0.9 & I8.o \\
\hline Serious & 33.5 & 23.0 & 31.9 & $3^{6.7}$ & 4I.3 & 30.0 \\
\hline Slight & $59 \cdot 7$ & $59 \cdot 5$ & 54.6 & 52.4 & 36.9 & $4^{8.0}$ \\
\hline No injury & $4 \cdot 3$ & I3.4 & IO.3 & 7.8 & I0.9 & 4.0 \\
\hline
\end{tabular}

T A B L E 4. Injury severity according to age in frontal and side impact crashes

\begin{tabular}{|c|c|c|c|}
\hline \multirow[b]{2}{*}{ Injury severity (MAIS level) } & \multicolumn{3}{|c|}{ Age group (years) } \\
\hline & $\mathrm{I} 7-39(\%)$ & $40-64(\%)$ & $65+(\%)$ \\
\hline \multicolumn{4}{|l|}{ Frontal impact crashes } \\
\hline $\mathrm{o}, \mathrm{I}$ & 73 & 67 & $4^{8}$ \\
\hline 2 & I4 & 20 & 23 \\
\hline 3 & 7 & 8 & I2 \\
\hline 4 & I & I & I3 \\
\hline 5 & I & I & 2 \\
\hline 6 & 3 & 3 & o \\
\hline Mean score & $I . I 3$ & 1.25 & I.68 \\
\hline \multicolumn{4}{|l|}{ Side impact crashes } \\
\hline $\mathrm{O}, \mathrm{I}$ & 68 & 70 & 47 \\
\hline 2 & I6 & I2 & 4 \\
\hline 3 & 6 & 5 & $2 \mathrm{I}$ \\
\hline 4 & I & I & II \\
\hline 5 & 5 & 5 & 7 \\
\hline 6 & 2 & 4 & II \\
\hline Mean score & 1.25 & 1.27 & 2.40 \\
\hline
\end{tabular}

Notes: MAIS is 'Maximum Abbreviated Injury Score'. Score 'o' is no injury, and score ' 6 ' is maximum (severest) injury. For an explanation, see text. The mean scores are calculated assuming that the average score for MAIS injuries is 0.5 .

Test statistics: Frontal impacts $\chi^{2}=68.6$, d.f. $=\mathrm{I} 2, p<$ 0.000I. Side impacts $\chi^{2}=22 . \mathrm{I}$, d.f. $=\mathrm{I} 2, p<$ 0.00I.

driver age group. Taking first frontal impact crashes, significant age group differences were found, and the older age group particularly sustained more severe injuries at MAIS level '4', although there were also higher percentages of injuries at levels ' 2 ', ' 3 ' and ' 5 '. A similar finding was established for side impact crashes, in which older drivers sustained more severe injuries, particularly at MAIS level ' 3 ' and above.

Injured body region and driver age

Given the differences in MAIS outcomes in both frontal and right-side impacts, further analyses have examined injuries to various parts of the 
T A B L E 5. Head and chest injury severity in frontal and side impacts by driver age

\begin{tabular}{|c|c|c|c|}
\hline \multirow[b]{2}{*}{ Injury severity (MAIS level) } & \multicolumn{3}{|c|}{ Age group (years) } \\
\hline & I7-39(\%) & $40-64(\%)$ & $65+(\%)$ \\
\hline \multicolumn{4}{|l|}{ Frontal impacts, head injuries } \\
\hline $0-2$ & 94 & 95 & $9^{\mathrm{I}}$ \\
\hline $3^{-6}$ & 6 & 5 & 9 \\
\hline \multicolumn{4}{|l|}{ Frontal impacts, chest injuries } \\
\hline $\mathrm{O}^{-2}$ & 94 & 93 & 76 \\
\hline $3^{-6}$ & 6 & 7 & 24 \\
\hline \multicolumn{4}{|l|}{ Side impacts, head injuries } \\
\hline $\mathrm{O}^{-2}$ & $9 \mathrm{I}$ & 89 & 89 \\
\hline $3^{-6}$ & 8 & 9 & II \\
\hline \multicolumn{4}{|l|}{ Side impacts, chest injuries } \\
\hline $0-2$ & $9 \mathrm{I}$ & $84 ? ?$ & 68 \\
\hline $3^{-6}$ & 8 & I4?? & 32 \\
\hline
\end{tabular}

Notes: MAIS is 'Maximum Abbreviated Injury Score'. Score 'o' is no injury, and score '6' is maximum (severest) injury. For an explanation, see text.

Chi-squared test statistics: Head injuries/MAIS in frontal crashes; $\chi^{2}=1.8_{3}$, d.f. $=2, p=$ n.s.

Chest injuries/MAIS in frontal crashes; $\chi^{2}=45.6$, d.f. $=2, p<$ o.ooor.

Head injuries/MAIS in side impact crashes; $\chi^{2}=0.79$, d.f. $=2, p=$ n.s.

Chest injuries/MAIS in side impact crashes; $\chi^{2}=\mathrm{I} 5.5$, d.f. $=2, p<$ o.ooI.

body. While all body regions were examined, for most the injury rates were statistically insignificant in each of the three age groups, while the most frequent injuries were to the head and chest. Table 5 shows the MAIS outcomes according to crash type and driver age group. Chisquared tests supported the null hypothesis that the distributions of head injury outcomes in frontal crashes did not differ by age group, but that there were significant differences for chest injuries. Compared to the other age groups, older drivers sustained more chest injuries at MAIS levels ' $3-6$ '. A similar result was found for side impact crashes. Contrary to intuitive expectations, there was no evidence that the driver head injury rates differed between the three age groups of drivers, but significant differences in chest injury rates were found. The older drivers had a higher rate of relatively severe injuries (MAIS ' $3-6$ ').

The influence of the steering wheel mounted airbag on head and chest injury outcomes was also examined in frontal crashes. As can be seen from Table 6, airbag deployment reduced relatively severe head injuries in all age groups. For drivers aged I $7-39$ years, the MAIS ' $3-6$ ' head injury rate in the non-deployed group was more than twice that in the deployed group. Among drivers aged 65 or more years, the rate increased from 4.3 per cent in the deployed group to 8 per cent in the non-deployed. Turning to chest injuries, the airbag marginally reduced injuries for 'young' drivers 
T A B L E 6. Influence of airbag on head and chest injury severity in frontal crashes

\begin{tabular}{|c|c|c|c|c|c|c|}
\hline \multirow[b]{3}{*}{$\begin{array}{l}\text { Injury severity } \\
\text { (MAIS level) }\end{array}$} & \multicolumn{6}{|c|}{ Age group (years) } \\
\hline & \multicolumn{2}{|c|}{ I7-39 } & \multicolumn{2}{|c|}{$4^{0}-64$} & \multicolumn{2}{|c|}{$65+$} \\
\hline & $\underset{\%}{\text { Airbag }}$ & $\begin{array}{c}\text { No airbag } \\
\%\end{array}$ & $\underset{\%}{\text { Airbag }}$ & $\begin{array}{c}\text { No airbag } \\
\%\end{array}$ & $\begin{array}{l}\text { Airbag } \\
\%\end{array}$ & $\begin{array}{c}\text { No airbag } \\
\%\end{array}$ \\
\hline \multicolumn{7}{|l|}{ Head injuries } \\
\hline $\mathrm{O}-2$ & 95 & $9^{2}$ & 95 & 95 & $9^{I}$ & 90 \\
\hline $3^{-6}$ & 2.2 & 4.7 & 3.0 & $4 \cdot 3$ & $4 \cdot 3$ & 8.0 \\
\hline \multicolumn{7}{|l|}{ Chest injuries } \\
\hline $\mathrm{O}^{-2}-2$ & 95 & 93 & $9 \mathrm{I}$ & 95 & 76 & 76 \\
\hline $3^{-6}$ & 2.5 & 4.7 & 6.0 & $4 \cdot 3$ & 20.0 & 22.0 \\
\hline Sample size & 279 & 320 & I66 & 185 & 46 & 50 \\
\hline
\end{tabular}

but not for the 'middle-aged'. The activation of airbags did not however appear to explain the major differentials in chest injury outcomes by driver age-group (shown in Table 5), since over 20 per cent of the older drivers sustained injuries at the MAIS ' $3-6$ ' level regardless of their deployment. Airbag effectiveness on chest injury outcome in side impact crashes was not studied since there were no instances of side airbag deployment in the sample.

\section{Injury outcomes and contact sources}

The presented findings suggest that the chest is the most vulnerable body region for older drivers. In the studied sample of older drivers, one-fifth or more in frontal crashes (regardless of airbag deployment), and one-third in right-side impact crashes, sustained injuries at the MAIS ' $3-6$ ' level. Table 7 is a cross-tabulation of the nature and contact source (or proximate agent) of these injuries by the Abbreviated Injury Scale (AIS) score among the younger and older age groups of drivers. The most common contact sources in frontal impacts were seat belts and steering wheels. For injuries at the AIS ' I' level, the main source among both young and old drivers was the seat belt, but for injuries at AIS ' $2+$ ' levels, while among older drivers the main source was also the seat belt, among young drivers the steering wheel was more often the agent. The influence of the airbag on these outcomes was considered but the paucity of the data prevented conclusive or informative findings. Table 7 also shows the contact sources by AIS severity in side impact crashes. Doors were the main source of contact for more severe injuries among both young and old drivers, an unsurprising result given the proximity of the driver to the door. 
T A B L E 7. Chest injury contact sources in frontal and side impacts by two age groups of drivers

\begin{tabular}{|c|c|c|c|c|}
\hline Abbreviated injury score & $\begin{array}{l}\text { Steering } \\
\text { wheel }(\%)\end{array}$ & Seat belt $(\%)$ & Door $(\%)$ & $\begin{array}{c}\text { Other } \\
\text { contact }(\%)\end{array}$ \\
\hline \multicolumn{5}{|c|}{ Drivers aged 65 or more years, frontal impacts } \\
\hline I & 7 & 89 & o & 4 \\
\hline 2 or more & 33 & 53 & $\mathrm{o}$ & I3 \\
\hline \multicolumn{5}{|c|}{ Drivers aged I7-39 years, frontal impacts } \\
\hline I & 8 & 80 & 0 & $\mathrm{I} 2$ \\
\hline 2 or more & $5^{2}$ & 33 & o & I5 \\
\hline \multicolumn{5}{|c|}{ Drivers aged 65 or more years, side impacts } \\
\hline I & o & 67 & 22 & II \\
\hline 2 or more & 0 & 9 & 74 & I7 \\
\hline \multicolumn{5}{|c|}{ Drivers aged I7-39 years, side impacts } \\
\hline I & o & $5^{8}$ & 24 & I6 \\
\hline 2 or more & o & 4 & 75 & $2 \mathrm{I}$ \\
\hline
\end{tabular}

T A B L E 8. Injury type in frontal and side impacts, by young and old drivers

\begin{tabular}{|c|c|c|c|}
\hline \multirow[b]{2}{*}{ Injury type } & \multicolumn{2}{|c|}{ Age group of drivers (years) } & \multirow{2}{*}{$\begin{array}{c}\text { Ratio } \\
65+/ 17-39\end{array}$} \\
\hline & I7-39(\%) & $65+(\%)$ & \\
\hline \multicolumn{4}{|l|}{ Frontal impacts } \\
\hline Surface injury only & 75 & $4 \mathrm{I}$ & 0.5 \\
\hline $\mathrm{AIS}_{2}+$ vessel injury & 4 & 2 & 0.5 \\
\hline $\mathrm{AIS}_{2}+$ organ injury & 8 & I3 & г. 6 \\
\hline Single rib fracture & 2 & 5 & 2.5 \\
\hline Multiple rib fracture & 4 & 18 & 4.5 \\
\hline Sternum fracture & 6 & $2 \mathrm{I}$ & 3.5 \\
\hline \multicolumn{4}{|l|}{ Side impacts } \\
\hline Surface injury only & $5^{\mathrm{I}}$ & 28 & 0.5 \\
\hline $\mathrm{AIS}_{2}+$ vessel injury & 8 & 9 & I.I \\
\hline $\mathrm{AIS}_{2}+$ organ injury & I8 & $3 \mathrm{I}$ & I.7 \\
\hline Single rib fracture & 7 & o & 0.0 \\
\hline Multiple rib fracture & I5 & $3^{\mathrm{I}}$ & $2 . \mathrm{I}$ \\
\hline Sternum fracture & 2 & o & 0.0 \\
\hline
\end{tabular}

Table 8 shows the injury types in frontal and side impact crashes by driver age group (younger or older). In frontal impacts, older drivers tended to sustain higher rates of AIS ' $2+$ ' organ injuries, particularly to the lungs, heart and myocardium, and higher rates of both single and multiple rib fractures and sternum fractures. In side impacts, similar age differentials were observed, but there was an even higher rate of AIS ' $2+$ ' organ injuries and multiple rib fractures in the older driver group compared to the younger driver group. 


\section{Discussion}

The findings of this study have shown that, on an assumption of similar vehicle crash conditions, older drivers are more at risk of fatal and serious injuries in both frontal and right-side impacts. The body region most prone to injury among older drivers in both frontal and side impact crashes was the chest. There was no discernible difference by age group in the rates of injury to any other examined body regions. Most notably, there does not appear to be an association between age and head injury rates and outcomes. Whilst this finding may appear counter-intuitive, little of the biomechanics head injury research provides support for the proposition that, for a given impact, head injury risk increases as a person ages.

This study suggests that changes in the design of vehicles are required to improve crash protection for older drivers. Existing chest injury mitigation devices such as driver airbags, side airbags and load-limiting seat belt systems may be beneficial but, to take into account age differences in the body's biomechanical tolerance of impacts, there is a case for refinements to seat belt systems. Possible methods include load-limiting or discretionary web-lock mechanisms, which as Mackay, Parkin and Scott (I994) have suggested, could be calibrated for specific occupant characteristics such as age, sex, weight and height. Such systems can recognise the age of the driver through key-card identification on entry to the vehicle. It will also be important to monitor how effectively recent vehicle safety systems, such as door- and seat-mounted side airbags, afford protection to elderly occupants.

More data from real world (or on road rather than laboratory) crash analyses will promote the understanding of injury patterns and crash outcomes for older adults, as also the relative protection afforded by various features of vehicle size and design. More specifically, it would be most useful to have more information about the relative frequency and severity of injuries by age of drivers in various crash configurations and vehicle designs. Such analyses would both improve the identification of the features that give effective crash protection, and be useful for advising older drivers on specific aspects of vehicle safety. Passenger safety also needs to be considered - this will be the subject of a follow-up study.

Given the need to encourage older drivers to acquire and use vehicles with modern safety features, a priority is to promote the awareness of vehicle safety issues amongst older people. The OECD (200I) report Ageing and Transport noted that, 'older drivers need information on the implications of ceasing to drive, on the physical and cognitive changes experienced as part of the ageing process, and on the choice of safer vehicles'. Recent surveys commissioned by the Australian Automobile Association (AAA) 
found a continuing belief that stronger and bigger cars offer more protection, and that smaller ones were less robust (AAA I997). In addition, it was not generally believed that new cars were safer than older cars, even though new expensive cars have superior safety features. The study also reported age differences in awareness and attitudes about crashworthiness and specific safety features. For example, when asked 'what aspects or features of a car help to make it safe in a crash?' only $5^{\mathrm{I}}$ per cent of drivers aged over 55 years spontaneously responded that specific safety features (such as airbags and seatbelts) were important, compared to over 75 per cent of drivers aged I8-33 years.

More recent research also shows that older people have a poor understanding of some of the safety features that are designed to protect the occupants of a vehicle in a crash (Charlton et al. 2002). The two key areas of misinformation and ignorance amongst among older people were about the safety benefits of airbags and vehicle design, including modern crumple zone structures. There is much scope for promoting the awareness of vehicle safety features across all age groups of drivers, but the need is clearly greatest among older people. If their awareness of vehicle safety features can be raised, this is likely to influence their vehicle purchases, and that should yield demonstrable safety benefits for both drivers and passengers.

Finally, it should be noted that this paper has discussed only secondary safety issues (i.e. injury avoidance). Primary safety issues (i.e. crash avoidance) also need to be considered for older drivers, particularly their receptiveness and adaptability to preventive designs (and driver education). Particularly relevant devices are collision-warning sensors, intelligent speed adaptation devices, fatigue sensors, lane departure warning systems, and structural design changes to improve visibility within the vehicle. Vehicle research and development on both primary and secondary safety devices should fully take into account the physiological and psychological changes in human ageing, so that vehicles can in the future be more safely and confidently used by all drivers.

\section{Acknowledgements}

This paper uses accident data collected for the United Kingdom Co-operative Crash Injury Study. CCIS is managed by TRL Limited, on behalf of the Department for Transport (Vehicle Standards and Engineering Division), which funds the project with Autoliv, the Ford Motor Company, Honda R\&D Europe, $\mathrm{LAB}$, Toyota Motor Europe, and the Volvo Car Corporation. The data were collected by teams from the Birmingham Automotive Safety Centre of the University of Birmingham, the Vehicle Safety Research Centre of the University of Loughborough, and the Vehicle Inspectorate Executive Agency of the (then) 
Department of the Environment, Transport and the Regions. Further information on CCIS can be found at http://www.ukccis.com/. The web site has abstracts of many conference papers based on the study. The authors gratefully acknowledge the statistical assistance of D.M. Starkings of The Open University (UK).

\section{NOTES}

I Equal to $50 \mathrm{~mm}$ of force-deflection on a Hybrid-III anthropomorphic crash-test dummy TE, the standard crash-test dummy used in regulatory vehicle compliance testing for frontal crash protection. 8,00o Newtons are equivalent to $80 \mathrm{~mm}$ of forcedeflection.

2 Frontal and side crashes comprise over 85 per cent of the cases on the CGIS database, and the analysis focuses on these crashes.

3 Measured as 'equivalent barrier speed' (or contact speed) in kilometres per hour.

\section{References}

Australian Automobile Association 1997. What are the Motorists Thinking? Report on I997 ANOP National Survey. ANOP Research Services, Australian Automobile Association, Canberra, Australia.

Augenstein, J. 200I. Differences in clinical response between the young and the elderly. Aging and Driving Symposium, Association for the Advancement of Automotive Medicine, Des Plaines, Illinois.

Berthel, M., Kuntzmann, F., Moyses, B. and Bouket, J. L. I980. La perte minérale osseuse liée à l'âge [Bone mineral loss according to age]. Médecine et Hygiène, 38, I828-31.

Charlton, J., Andrea, D., Fildes, B., Morris, A., Oxley, J., Langford, J. and Johnson, L. 2002. Safe Vehicle Choices for Older Adults. Royal Automobile Club of Victoria, Melbourne, Victoria, Australia.

Cunningham, C., Howard, D., Walsh, J., Coakley, D. and O’Neill, D. 200I. The effects of age on accident severity and outcome in Irish road traffic accident patients. Irish Medical Journal, 94, г69-7і.

Dejammes, M. and Ramet, M. 1996. Aging process and safety enhancements of car occupants. In Proceedings of I5th Conference on 'Enhanced Safety in Vehicles'. Melbourne, Australia, г189-96.

Diamantopoulou, K., Skalova, M., Dyte, D. and Cameron, M. 1996. Crash Risks of Road User Groups in Victoria. Report 88. Monash University Accident Research Centre, Melbourne, Victoria, Australia.

Evans, L. I99I. Traffic Safety and the Driver. Van Nostrand Reinhold, New York.

Fildes, B. N., Fitzharris, M., Charlton, J. and Pronk, N. 20or. Older driver safety: a challenge for Sweden's 'vision zero'. In Proceedings of the Australian Transport Research Forum. Hobart, Australia, unpaginated compact disc.

Foret-Bruno, J.-Y. I978. Correlation between thoracic lesions and force values measured at the shoulder of 92 belted occupants involved in real accidents. In Proceedings of 22nd STAPP Car Crash Conference. Ann Arbor, Michigan, 27I-92.

Foret-Bruno, J. Y., Brun-Cassan, F., Brigout, C. and Tarriere, C. I989. Thoracic deflection of Hybrid III dummy response for simulations of real accidents. In Proceedings of I 2 th Experimental Safety Vehicles Conference. Gothenburg, Sweden, 650-6o. 
Hu, P., Jones, D., Reuscher, T., Schmoyer, R. and Truett, T. 200o. Projecting fatalities in crashes involving older drivers. Report for the National Highway Traffic Safety Administration, Oak Ridge National Laboratory Report 6963. Oa Ridge, Tennessee.

Mackay, G. M. I989. Biomechanics and the regulation of vehicle crash performance. In Proceedings of 33rd Association for the Advancement of Automotive Medicine Conference. Baltimore, Ohio, 323-36.

Mackay, G. M. and Hassan, A. M. 200o. Age and gender effects on injury outcome for restrained occupants in frontal crashes: a comparison of UK and US databases. Proceedings of the Association for the Advancement of Automotive Medicine 44th Conference. Chicago, 75-9I.

Mackay, G. M., Parkin, S. and Scott, A. I994. Intelligent restraint systems: what characteristics should they have? In Advances in Occupant Restraint Technologies. Joint Association for the Advancement of Automotive Medicine and the International Research Council on the Biokinetics of Impacts, Special Session, Lyon, France, I13-26.

Mitchell, G. C. B. 2000. Some implications for road safety of an ageing population. In Transport Trends 2000, Department of the Environment, Transport and the Regions, London, 26-34.

Organisation for Economic Co-operation and Development (OECD) 2001. Ageing and Transport: Mobility Needs and Safety Issues. OECD, Paris.

Padmanaban, J. 200r. Crash injury experience of elderly drivers. In Proceedings of the Ageing and Driving Symposium. Southfield, Michigan. Association for the Advancement of Automotive Medicine, Des Plaines, Illinois, unpaginated compact disc.

Viano, D., Culver, C. C., Evans, L., Frick, M. and Scott, R. I989. Involvement of older drivers in multi-vehicle side impact crashes. In Proceedings of 33 rd Association for the Advancement of Automotive Medicine Conference. Baltimore, 337-52.

Accepted 3 February 2003

Address for correspondence:

Andrew Morris, Vehicle Safety Research Centre,

Ergonomics and Safety Research Institute, Holywell Building, Holywell Way, Loughborough University, Loughborough LEı I 3 UZ, UK.

e-mail: a.p.morris@lboro.ac.uk 